\title{
A Conceptual Metonymy Account of Count and Non-Count Nouns: A Study of Modern Greek Nouns from the Domains of Eating and Drinking
}

\author{
Ifigeneia Athanasiadou and Martha Lampropoulou \\ Aristotle University of Thessaloniki \\ aifigene@enl.auth.gr,marthalamp@gmail.com
}

\begin{abstract}
The aim of the paper is to examine how conceptual metonymy influences the way food and drink nouns are conceptualized as count or non-count in specific utterance contexts. The nouns examined are the following: tsai (tea), gala (milk), kafes (coffee), nero (water), fakes (lentils), fasolia (beans), arakas (peas), sitari (wheat), vromi (oats), halvas, and zeles (jelly). The sentences are either constructed examples or borrowed from the Hellenic National Corpus (HNC). The paper is grounded on Idealized Cognitive Models (Lakoff 1987) and on the model of conceptual metonymy (Radden and Kövecses 1999).
\end{abstract}

\section{Introduction}

The paper is an attempt to identify countability preferences as motivated by the use of conceptual metonymies. Countability should not be claimed to be a "black or white" issue. Instead of being either countable or not, most food and drink nouns in Modern Greek oscillate between a countable and non-countable conceptualization depending on the respective Idealized Cognitive Model.

Substance-mass nouns, like coffee or water, typically receive amount quantification, since the real-world physical substance they refer to can only be conceptualized as extending to an unbounded, continuate stretch of space (Hirtle 1982: 76-77). Yet, this is not always the case since mass-to-count countability shifts are often observed, leading to a non-count noun being used in a count-noun syntactic frame. For instance, even if water ('nero') is a noncount noun, in the ICM of a container (glass, bottle, etc.), water can turn into a countable noun, namely, "two waters"('dio nera'), metonymically referring to two glasses of water or two bottles of water.

(cc) BY-NC-ND 


\section{Theoretical Background}

Structural and transformational approaches consider the language faculty as an independent component of the human mind with its own self-contained structure and function (Taylor 1995: 16). One would wonder, though, how language could possibly be independent of what it stems from. As Geeraerts (2006: 5) very aptly puts it: "language use is undeniably related to human experience and perception of the outside world and linguistic meaning, among other things, is encyclopedic, in that, it results from our world knowledge".

The major principles (Geeraerts 2006: 7-20) that characterize the theoretical background of the paper are presented below. In the first place, linguistic meaning is perspectival, i.e. the same situation may be conceived differently by different speakers since every single speaker uses his/her own idiolect sourcing from his/her perspective, e.g. by asking for " a water" ('ena nero') a speaker may implicitly refer to a glass of water or a bottle of water.

Secondly, linguistic meaning is dynamic and flexible. Etymological research revealed that the noun tsai (tea) was firstly introduced in Greece in the $18^{\text {th }}$ century (Andriotis 1995: 378). Similarly, the word 'tea' and the practice of drinking tea was first introduced in England in 1644, while in 1738 the word carried the meaning "afternoon meal at which tea is served" (Online Etymological Dictionary).

Thirdly, language use uncovers social and cultural identities, in that, language use reflects the world as it is experienced by the norms of every single society. For example, oats ('vromi') is a plural-only noun in English while the equivalent word is singular-only in Greek. English speakers focus on the discrete oat grains while Greek speakers highlight its collective denotation (Athanasiadou 2009:39).

This paper is based on two crucial factors of the Cognitive Linguistics framework, namely, grammatical patterns are triggered by conceptual and pragmatic factors and, more specifically, metonymy and metaphor may have some impact on grammatical form (Panther and Thornburg 2009: 4-5).

\section{Conceptual Metonymy}

A rather popular definition of conceptual metonymy is provided by Lakoff (1980: 35): "Using one entity to refer to another that is related to it" [e.g. The ham sandwich is waiting for his check (= the client who ordered the ham sandwich)]. During metonymic processes, the mapping between the two entities is realized within a single conceptual domain. In other words, the name of one entity is used to refer to another entity that is contiguous to it. Thus, metonymy can be considered as having a reference function.

Metonymy is based on contiguity, that is actual proximity or association (Geeraerts 2006: 13). This means that the substitution of one term for another depends on a kind of association or relation between the two terms. 
For Croft (1993), contiguity reveals that encyclopedic knowledge is organized into domains and, as far as metonymy is concerned, two domains interact, a matrix domain and a subdomain. For Panther and Thornburg (1999), contiguity shows that our knowledge is classified in terms of frames and scenarios. And, for Lakoff (1987: 288), contiguity can be explained by means of Idealized Cognitive Models and conceptual domains, as will be discussed below.

For Radden and Kövecses (1999), which is the approach adopted in the paper, metonymy occurs when an idealized cognitive model is activated. In other words, Idealized Cognitive Models involve any possible associations stimulated in our mind. Suppose we use the word 'tea' and we think of the 'tea ICM'. The latter may, among many other things, refer to "a cup of tea" (Container ICM) or to a "gathering of friends to drink tea" (Event ICM). ICMS, the outcome of a one-to-one correspondence mapping between concepts, entities, and things, could be classified into three broader categories (Radden and Kövecses 1999: 24-28): a) sign ICMs and sign metonymies, e.g. using the word 'dollar' for money in general b) reference ICMs and reference metonymies, e.g. using the word 'cow' to refer to the real-world cow; both the word 'cow' and the concept of the animal function as reference for the actual cow one perceives visually c) concept ICMs and conceptual metonymies, e.g. employing the word 'bus' to refer to bus-drivers in general. The concept ICMs constitute the focus of the paper.

\subsection{Why Metonymy for Countability}

Since metonymy is based on substitution and on a contiguous relationship between two terms, it seems that it could reveal the countability preferences one has in mind when he or she uses count or non-count nouns. In other words, it will uncover the target term speakers have in mind, namely, a discrete unit or a continuous substance, when, for example, asking for "a glass of water" or "water"; in this respect, Langacker (1993:30) emphasizes the need to be accurate and argues that metonymy allows for an efficient reconciliation of two conflicting factors: that of being sure that the addressee's attention is directed towards the intended target and that of our natural inclination to think and talk explicitly about those entities that have the greatest cognitive salience for us.

\subsection{Idealized Cognitive Models: How Metonymy Accounts for Count and Non-count Nouns}

Depending on the metonymic relationships being used, one would observe that countability preferences vary according to the corresponding setting. However, 
commonalities in the way food and drink count and non-count nouns are conceptualized and expressed occur due to the scenarios they are part of. Such scenarios mostly have to do with: a) ordering at restaurants, taverns, cafeterias b) purchasing goods c) means of collecting goods or referring to their properties or to the type of goods in a generic sense.

\section{Nouns and Countability}

In order to clarify the notion of countability, it would be helpful to explore the way nouns, or else nominal predications, are presented in the framework of Cognitive Linguistics.

According to Langacker (1987: 183), nominal predications designate things whereas relational predications designate atemporal relations or processes. Things not only refer to physical objects in the real world but to abstract cognitive events as well. In detail, a thing occupies a region in some domain. A region is defined schematically as a set of interconnected entities (Langacker 1991: 15).

Cases where the profiled region is conceptualized as being bounded in a primary domain are characterized grammatically as prototypical count nouns (Langacker 1987: 189). Prototypical count nouns refer to physical objects in the real-world. Something is construed as being a bounded region because the conceptualizer imposes a "virtual boundary" in framing a conceived situation (Langacker 1987: 196).

On the contrary, non-count nouns, while occupying a region in some domain, this region is characterized by internal homogeneity and construed as a continuous uniform whole. Prototypical non-count nouns refer to physical substances in the real-world. The specification of a boundary is vital to the distinction between count and non-count nouns. Overall, the ontological distinction between the two principal types of things, namely, objects and substances, is reflected in the grammatical distinction between count and noncount nouns.

Radden and Dirven (2007: 72) refer to a type-of relation. Since a physical substance can be conceptualized as a discrete object, the respective noun denoting the continuous substance can be pluralized like any other count noun referring to a real-world physical object. A bounded discrete amount of a substance can stand for a variety or type of that substance. A singular mass noun, when pluralized, refers to different varieties or types of that substance. However, notice that substances construed as objects do not occupy space in the way prototypical objects do but that they are delimited by the containers they are placed in.

Bearing in mind the aforementioned approaches with respect to the conceptualization and use of food and drink nouns, the analysis that follows 
attempts an approach to countability by means of a metonymic model (Radden and Kövecses 1999).

\section{Analysis}

The formation of ICMs results in the use of metonymies. The relationships that give birth to metonymies are called metonymy-producing relationships. The metonymies produced are various and may overlap. However, two major configurations can be distinguished (Radden and Kövecses 1999: 30):

(i) the formation of a whole ICM via its parts. For example, one may say: "the lightning of the Christmas tree" instead of "the lightning of the candles on the Christmas tree"

In this case, the Whole is the Christmas tree, while the Part is the set of candles. Despite the fact that speakers are aware that the candles are lightened, they refer to the tree as being lightened itself.

And

(ii) the formation of a part of an ICM via its whole. For example, one may utter: "those are cool wheels you have there" instead of "you have got a cool high speed car"

In this example, the Part is the wheels, while the Whole is the car. The speaker uses the Part, namely, the wheels, instead of the Whole, that is the car.

Or

Some commonly used words may function metonymically, such as hand for control:

e.g. Things got out of hand.

Similarly, the hand is the Part which stands for the Whole, which is the word 'control'.

These two configurations apply to all metonymic relationships. Hence, despite the fact that a metonymic relationship is either a Whole for Part or a Part for Whole metonymy, the particular metonymic relationship should be further classified with regard to the metonymic type it complies with. For instance, it should be specified whether it is an Event ICM or a 'Category and Member' ICM. An ICM type that could cover most of the examples in the paper seems to be the Event ICM since it comprises all the main activities typically encountered in ordinary food and drink contexts: ordering, purchasing, and collecting goods "see Section 3.2"

\subsection{Event ICM (Radden and Kövecses 1999: 32)}

In the utterance: I am drinking milk, one can observe the following metonymic configuration: 
It is a 'Part for Whole' metonymy and more specifically an Event ICM. The event taking place involves the common scene of: having breakfast in the dining room or the kitchen and drinking a glass of milk or having two mugs of milk. By using a bare substance-mass noun, that is milk, the speaker focuses on the event and not on the amount of the liquid he or she is having, namely, the glass or the mugs. The use of the word 'milk' functions metonymically. Thus, the Part is the subevent of drinking something; in particular, milk. I am drinking milk. Contrary to the Part, the Whole event comprises many more details that can easily be represented in the speaker's mind without being specified. The use of the singular shows that the speaker focuses on the event, not on the amount of the liquid s/he is drinking.

(1) 'Eva vepó $\sigma \tau о$ o 6.

'A water for 6'.

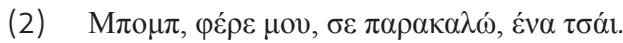

'Bob, bring me a tea, please'.

In examples (1) and (2) a restaurant or a café 'frame' is being indicated and an Event ICM is being constructed, that of ordering something to drink. We do not clarify the amount of the substance to be served, yet, the speaker highlights a countable conceptualization of both drinks. Obviously, whenever we order " $a$ water" ('ena nero'), or "a tea" ('ena tsai') a bounded amount of the respective substance is being implied. But, do we mean a glass of water, a bottle of water, or still something else? Only by finding ourselves in the relevant 'frame' can we mentally access the denoted container, be it a glass or a bottle.

In (1) even if we use the amount quantifier "a" ('ena'), we still do not know the exact container the water is to be placed in. The "type of serving" of the water (Tsoulas 2007:2) is not explicitly mentioned but evokes from an Event-ICM. Hence, in the particular example, a Containment ICM could also be activated under the Event ICM "see Section 5.2"

In (2) we can assume various scenarios. For instance, the scenario of being in a tea-house and asking to buy some tea, or being in a field seeded with tea (a tea plantation) and collecting tea. Both Event ICMs facilitate the speaker to conceptualize a package or a handful of tea, respectively. In other words, a bounded amount of tea is implied and the Event ICMs trigger the singular use of

1 The Greek example sentences are translated in their English equivalents, except for the ones preceded by a question mark which are a word-for-word translation of the original utterance. 
the word 'tea' which, in turn, enables the speaker to omit a lot of the scenario's details.

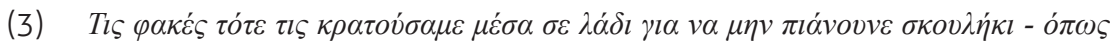

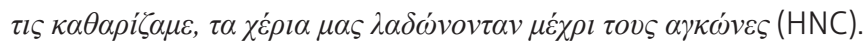

'We used to keep lentils in oil so that worms wouldn't eat them and as we were cleaning them, grease would drip from our palms till our elbows'.

The substance-mass noun lentils ('fakes') illustrates an Event ICM, that is the way of producing and preserving the plant lentils. Notice that lentils is used in a plural count-noun sense since the lentils are conceptualized as discrete grains in this case, they are thus not an ingredient of a lentil soup or of another kind of food. The Event ICM of preserving and cleaning the separate lentil grains enables and probably requires the use of the plural.

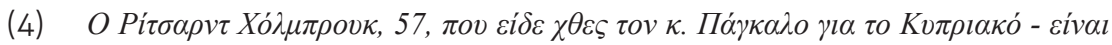

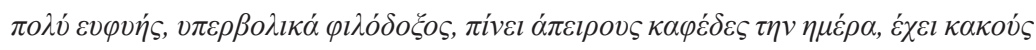

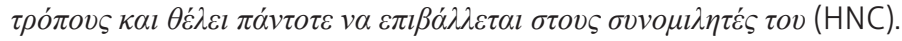

'Richard Holbrook, 57, who met Mr. Pagkalos yesterday to discuss the Cypriot issue - is very intelligent, drinks numerous coffees per day, has bad manners and always wants to keep control of his interlocutors'.

In (4), we have the Event ICM (Lakoff and Johnson 1980:15-20) since coffees stands for the drinking of many coffees on a daily basis. In other words, the substance stands for the numerous events that are characterized by its consumption. It is also a 'Part for Whole' metonymy: Part = the subevent of having coffees, Whole $=$ the scenario of consuming many coffees on a daily basis.

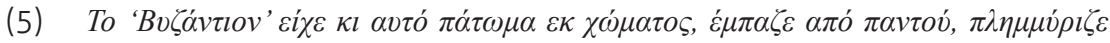

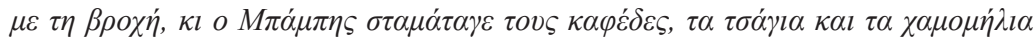

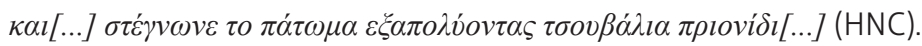

"Vyzantion' had a muddy floor, and water used to come in from everywhere, so Babis would stop boiling the coffees, the teas and the chamomiles and $[\ldots .] d r i e$.$d the floor by throwing bags of sawdust[...]'.$

Example (5) is a 'Part for Whole' metonymic configuration as well as an Event ICM. It is a 'Part for Whole' metonymy since only the unbounded liquid substance is denoted instead of the scene of the preparation and serving of the drinks in their containers. The content, such as the coffee or the tea substance, metonymically leads to the preparation of three different kinds of drinks and their serving in containers, such as a cup of coffee or a cup of tea or a teapot, and results in building an Event ICM. The action verb 'stop', which refers to 
the ceasing of the preparation of drinks, enhances the sense of an event taking place, making the Event ICM more prominent.

Nevertheless, whenever the speaker chooses to direct his or her attention to the individual food and drink nouns, and not on the entire event, the Containment ICM is being activated, as discussed below.

\subsection{Containment ICM (Radden and Kövecses 1999: 41)}

In the containment ICM, what is of great importance is the notion of a container that functions as the vehicle through which we mentally access the respective substance, that is the target. Langacker (1991: 30) claims that "the greater the conceptual contrast between vehicle and target, the better is the relationship to be exploited metonymically".

Content for container: The milk tipped over (Norrick 1981: 58).

Containment ICM: Someone is shopping in a supermarket when, by accident, the milk container tips over (Norrick 1981: 58).

Content: milk

Container: milk carton (implied)

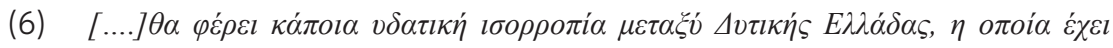

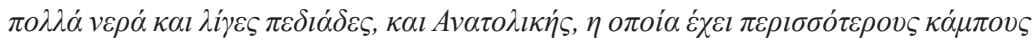

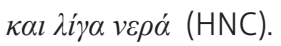

'[....] it will bring a kind of water balance between Western Greece, an area with many waters and few plains, and Eastern Greece, an area with much more plains and few waters'.

In (6), the singular non-count noun water ('nero') is used in a plural countnoun sense, namely, waters ('nera'). It is a 'Whole for Part' metonymy because the substance here acquires its generic sense. The reference is the element of water, which is the Whole, stands for a limited amount found in lakes or rivers. Thus, lakes and rivers is the implied Part.

Additionally, the 'Content for Container' metonymy motivates the use of the plural, that is waters ('nera'). Content is the water while Container is a lake or a river. The 'Content for Container' metonymic model (Radden and Kövecses 2009: 41) is usually employed where water as an unbounded physical substance metonymically extends to the bounded water containers, such as lakes or rivers.

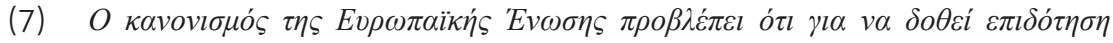

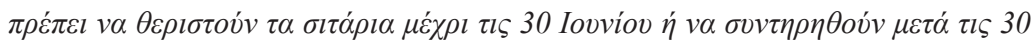
Iovvíov (HNC). 
'The regulation of the European Union stipulates that in order to grant a subsidy, the wheats should be harvested till the $30^{\text {th }}$ of June or stored and kept after the $30^{\text {th }}$ of June'.

In (7), we could schematically be transferred to a scene of fields where wheat is cultivated. By using the singular substance-mass noun wheat ('sitari') as a plural-count noun, namely, wheats ('sitaria'), we metonymically refer either to the plurality of fields seeded with wheat or to the wheat kernels that need to be harvested. Thus, the use of the plural activates two ICMs:

1) The first involves the number of fields that could be visualized in the speaker's mind. This is a 'Whole for Part' metonymy: the Whole is the fields seeded with wheat, and the Part is the wheat kernels. Apart from being a 'Whole for Part' metonymy, it is also a 'Container for Content' ICM: container-fields, content-wheat kernels. The speaker illustrates the harvesting of the fields that in fact stands for the harvesting of the wheat kernels.

2) The second metonymic mapping is observed when the discrete kernels of wheat, and not the plurality of fields, are visualized by the speaker. A 'Part for Whole' metonymy and the 'Content for Container' ICM are constructed: contentwheat kernels, container-fields. The speaker refers directly to the kernels of wheat. Overall, in example (7), the speaker determines what he needs to refer to, either the Content (wheat) or the Container (fields).

As observed in (6) and (7), the 'Content for Container' metonymically leads to different kinds of bounded containers.

It is also worth noting that the singular substance-mass noun arakas (peas) has no grammatical plural form (? arakades). However, arakas could also be pluralized, motivated by the appropriate Event ICM or 'Content for Container' ICM, when referring to packs of the product used for its containment:

(8) Пои́ દ́ $\beta \alpha \lambda \varepsilon \varsigma \tau o v \varsigma \alpha \rho \alpha \kappa \alpha ́ \delta \varepsilon \varsigma ;$

'Where did you put the peas?'

However, there are types of physical substances where the 'Content for Container' ICM is not so frequently applied. For instance, halvas and jelly ('zeles'), two types of sweets are not that easily conceptualized in a kind of container due to their thick liquid nature:

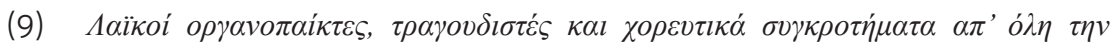

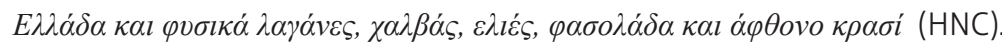
'Folk musicians, singers and dancing groups from all over Greece and, of course, laganes, halvas, olives, beans soup and plenty of wine'. 


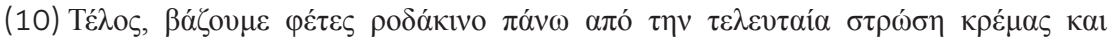

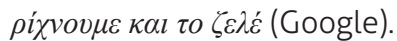

'Finally, we place slices of peach on top of the last cream layer and we pour the jelly'.

However, both nouns can be encountered in the plural, even if the substances denoted are mostly conceptualised as a uniform whole. For instance:

(11) $E \beta \alpha \lambda \varepsilon \varsigma \tau o v \varsigma \zeta \varepsilon \lambda \varepsilon ́ \delta \varepsilon \varsigma \sigma \tau o \psi v v \gamma \varepsilon i o$;

? 'Did you put the jellies in the fridge?'

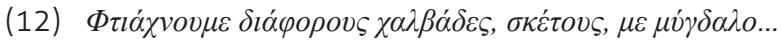

? 'We produce various halvades, pure, with almond...'

In (11) and (12), the 'Content for Container' ICM is being used. The relevant containers, enclosing jellies or halvades, such as bowls or pots, are being backgrounded. Instead, the uniform mass substance is being foregrounded.

It has to be noted here that halvas and zeles (jelly) are not real Greek words; they are, actually, loan words. Yet, despite their origin and their non-count nature, they can receive the plural inflection in the 'Content for Container' ICM.

\subsection{Category and Member ICM (Radden and Kövecses 1999: 34)}

Radden and Kövecses exemplify this type by means of the following examples:

'Generic for Specific': "Boys don't cry"

'Specific for Generic': "A/ The spider has eight legs"

The authors elaborate on the first example sentence by explaining that the statement about the boys can be used in a particular occasion when a boy is crying and, thus, the statement is perceived specifically. However, in the second example sentence, the authors claim that "specific tokens may be used to stand for generic types" since "the definite article the or the indefinite $a$ are used to refer to spiders in general" (Radden and Kövecses, 1999: 34).

In the domain of food and drinks, the type 'Specific for Generic' can be observed when reference is made to a specific plant or vegetable which stands for a type of drink or food extending to an entire category with certain properties. The use of the singular is mostly employed in order to refer to these types of drinks or foods having specific properties, as illustrated in the following examples: 


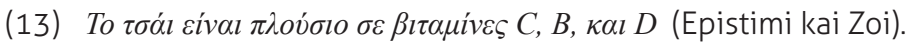

'Tea is rich in vitamins $C, B$, and $D$ '.

Generic: The statement is valid for every tea-plant.

Specific: The utterance becomes specific when spoken at a specific moment in time for a specific tea-plant or drink representing every-tea plant or tea-drink.

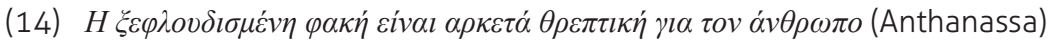

'Peeled lentils are very nutritional for man'.

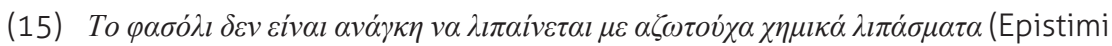
kai Zoi).

'Beans do not need nitrogenous chemical fertilizers'.

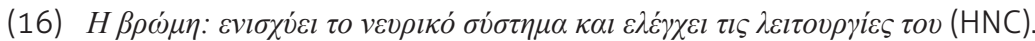

'Oats: they boost the neural system and control its functions'.

From a semantic point of view, Wierzbicka (1985: 329) underlines that although beans is a plural-mostly noun and oats is a plural-only noun, both types of nouns are conceptualized only in a collective, not in an individual, sense.

In Modern Greek, the semantic meaning of the noun 'faki' (lentils), bearing a collective sense, remains the same, either in the singular, namely, faki (lentils), or in the plural, that is fakes (lentils). Fasoli (bean) can also have a plural form, namely, fasolia (beans), unlike vromi ('oats'), which cannot have a plural form (? vromes). The physical size of the real-world referents of the relevant nouns could explain this observation since individual beans are bigger than oat grains (Wierzbicka 1988: 535).

In examples (14)-(16), the 'Category and Member ICM' is projected. Each one of the relevant nouns, namely, faki (lentils), fasoli (bean), and vromi (oats), is employed in the singular to refer to a distinct type of food. These nouns function as a member of a category highlighting beneficial health effects, (14) and (16), or the required conditions for cultivating the plant (15).

\subsection{Production ICM (Radden and Kövecses 1999: 39)}

In the particular type of metonymic relationship, the producer, be it the owner of a business or a brand name, usually replaces the product itself. In such cases, the brand name or the business owner is famous and widely known. Furthermore, the brand name is encountered mostly in the singular, which is retained even if the speaker implies a number of products of this brand. 
'Producer for Product' ICM: Agoazo agno me 1,20 to litro.

? 'I buy Agno with 1,20 per litre'.

'Producer for Product' ICM: The producer is the dairy products company 'Agno', which metonymically stands for its product, namely, milk.

Producer: The dairy products company 'Agno'

Product: milk

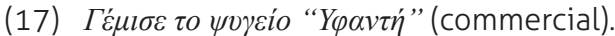

? 'Fill the refrigerator with "Ifanti".

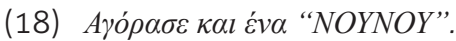

? 'And, also, buy a 'NOUNOU'.

In (17), Ifanti, which is the producer's or the brand's name, metonymically triggers either a specific type i.e. turkey fillet or other types of the product i.e. ham or sausages. The specific quantity required is not explicitly mentioned and the use of the singular implies an unbounded mass quantity of the product.

Once more in (18), the 'Producer for Product' conceptual metonymy is in use. However, in this case, the brand name 'NOUNOU', which is the producer and is preceded by the numeral ena (one), metonymically stands for a specific product. For Radden and Kövecses (1999: 39) the 'producer' can either be replaced by the brand's name ('NOUNOU') as in (18) or the producer's name ('Ifanti') as in (17).

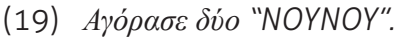

? 'Buy two 'NOUNOU".

'NOUNOU', cannot receive a plural inflection, even if we actually refer to two cartons or bottles of milk. This is often observed, especially when the brand's or the manufacturer's name is not in Greek, and hence the noun remains in the singular. Even though the brand name remains in the singular, the use of the number quantifier dio (two) extends to two instances of the same product.

\section{Concluding Remarks}

In all of the examples presented in the paper, there is a scenario, or else, a frame of eating or drinking, which is a primitive and non-culturally specific human experience. The types of food and types of drinks exemplified in the study can either be treated as count or non-count according to the Idealized Cognitive Model employed in the relevant context. 
More specifically, the Event ICM and the 'Content for Container' ICM seem to motivate both the use of the singular and the plural regardless of the fact that some of the foods and drinks constitute discrete particles while others form a homogeneous mass. For instance, concerning the Greek food nouns fasolia (beans) and faki (lentils), there is not a particular grammatical number preference since both the singular and the plural forms can well be used interchangeably, hence fasoli-fasolia and faki-fakes.

Similarly, turning to the domain of drinks, types of drinks, such as nero (water), and kafes (coffee), undoubtedly constitute a continuous mass, yet, when the frame or else, the ICM calls for a container, then, they can be perfectly enumerated giving rise to the use of plural inflection, hence nero-nera and kafeskafedes.

However, the 'Specific for Generic' ICM, which is a subtype of the 'Category and Member' ICM, and the 'Producer for Product' ICM seem to favor mostly the use of the singular, as shown in the analysis of the example utterances, "see Section 5.3" and "Section 5.4", respectively.

We cannot overlook the fact that linguistic categories influence non-linguistic behavior, such as non-verbal thought processes. According to the Sapir-Whorf Hypothesis, language can influence thought and underlie our conceptualizations (Lucy and Gaskins 2003). Speakers across cultural groups may construe and use a noun as count or non-count, depending on how their language encodes the real-world referent of the relevant noun.

It appears that, not only across cultures but also within a cultural group, speakers display countability preferences based on criteria of functionality and economy of language use in accordance with a certain type of ICM. Speakers of Modern Greek use a noun as count, arakades (peas), or non-count, arakas (peas), according to the functional needs of the specific utterance context.

All of the example nouns from the domain of food and drinks examined in the study were shown to be encountered in both the singular and the plural in a certain type of ICM. This fact reveals that Greek speakers are flexible enough in noun countability shifts and that they can accommodate the noun's countability status to the corresponding utterance context.

Metonymy appears to be an efficient means of communicating meaning since, especially in the domain of food and drinks, it achieves accuracy, clarity, relevance, and economy of use, at the same time².

2 We would like to thank Kyriaki Kourouni for the reviewing of the example sentences presented in the paper and Angeliki Athanasiadou for her invaluable advice and support. 


\section{References}

Andriotis, N.P. 1995. Etymologiko leksiko tis koinis neoellinikis [Etymological Dictionary of Standard Modern Greek]. $3^{\text {rd }}$ edition. Aristotle University of Thessaloniki: Institute for Modern Greek Studies.

Anthanassa. Retrieved 20 August 2012 from <http://www.anthanassa.gr/ articles/articles.html>

Athanasiadou, I. 2009. Count and Non-count Nouns in Greek and in English. A thesis submitted for the degree of MA by Dissertation. University of Essex. United Kingdom.

Croft, W. 1993. The role of domains in the interpretation of metaphors and metonymies. Cognitive Linguistics 4(4): 335-370.

Egkiklopedia Epistimi kai Zoi [Encyclopedia 'Science and Life']. Vol. 18. Chatziiakovou (ed.). Thessaloniki and Athens: Chatziiakovou. 83,194.

Geeraerts, D. 2006. Cognitive Linguistics: Basic Readings. Berlin: Mouton de Gruyter.

Hellenic National Corpus (HNC). Retrieved 10 March 2011 from < http://hnc.ilsp.gr>

Hirtle, W.H. 1982. Number and inner space: A study of grammatical number in English. Quebec: Les Presses de l’Université Laval.

Lakoff, G. and Johnson, M. 1980. Metaphors we live by. Chicago: The University of Chicago Press.

Lakoff, G. 1987. Women, Fire, and Dangerous Things. Chicago: The University of Chicago Press. 
Langacker, R.W. 1987. Foundations of Cognitive Grammar, Vol. I. California: Stanford University Press.

Langacker, R.W. 1991. Foundations of Cognitive Grammar, Vol.II. California: Stanford University Press.

Langacker, R.W. 1993. Reference-point constructions. Cognitive Linguistics 4(1): $1-38$.

Lucy, J.A. and Gaskins, S. 2003. Interaction of Language Type and Referent Type in the Development of Nonverbal Classification Preferences. In D. Gentner and S. Goldin-Meadow (eds.). Language in Mind: Advances in the Study of Language and Thought. Cambridge MA:MIT Press, 465-492.

Norrick, N.R. 1981. Semiotic Principles in Semantic Theory. Amsterdam / Philadelphia: John Benjamins Publishing Company.

Online Etymological Dictionary. Retrieved 13 March 2011 from <http://www. etymonline.com/index. php?term=tea>

Panther, K.-U. and Thornburg, L. 1999. The Potentiality for Actuality Metonymy in English and Hungarian. In K.-U. Panther and G. Radden (eds.). Metonymy in Language and Thought. Amsterdam/ Philadelphia: John Benjamins Publishing Company, 333-357.

Panther, K.-U. and Thornburg, L. 2009. On figuration in grammar. In K.-U. Panther, L.L. Thornburg, and A. Barcelona (eds.). Metonymy and Metaphor in Grammar. Amsterdam/Philadelphia: John Benjamins Publishing Company, 1-44.

Radden, G. and Dirven, R. 2007. Cognitive English Grammar. Amsterdam/ Philadelphia: John Benjamins Publishing Company.

Radden, G. and Kövecses, Z. 1999. Towards a theory of Metonymy. In K.-U. Panther and G. Radden (eds.). Metonymy in Language and Thought. Amsterdam/ Philadelphia: John Benjamins Publishing Company, 17-59.

Taylor, J.R. 1995. Linguistic Categorization. New York: Oxford University Press.

Tsoulas, G. 2007. On the grammar of number and mass terms in Greek. Retrieved 23 March 2011 from <http://thesource.dlp.mit.edu:16080/greeksynsym/ papers/Tsoulas.pdf> 
Major Trends in Theoretical and Applied Linguistics

Wierzbicka, A. 1985. Oats and wheat: The fallacy of arbitrariness. In J. Haiman (ed.). Iconicity in Syntax. Amsterdam/Philadelphia: John Benjamins Publishing Company, 311-340.

Wierzbicka, A. 1988. The semantics of grammar. Amsterdam/Philadelphia: John Benjamins Publishing Company. 